\title{
NATURAL COMPOUNDS OF PALESTINE FLORA. COMPARISON ANALYSIS BY STATIC HEADSPACE AND STEAM DISTILLATION GC-MS OF SEMIVOLATILE SECONDARY METABOLITES FROM LEAVES OF CULTIVATED PALESTINIAN MAJORANA SYRIACA
}

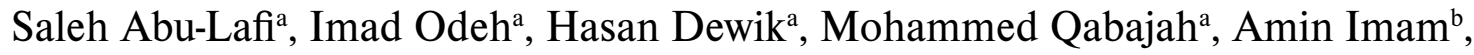 \\ Valery M. Dembitskyc, Lumir O. Hanus ${ }^{\mathrm{d} *}$
}

a Chemistry and Chemical Technology Department, P.O. Box 20002, Al-Quds University, Abu-Deis, Palestine

b Techno-Line Advanced Instrumentation, P.O. Box 27292, East Jerusalem, Palestine

c Department of Organic Chemistry, P.O. Box 39231, Hebrew University of Jerusalem, Jerusalem 91391, Israel

¿ Department of Medicinal Chemistry \& Natural Products, School of Pharmacy, 12065, Hebrew University, Jerusalem 91120, Israel

e-mail:lumir@cc.huji.ac.il

Received: March 23, 2007; Accepted: April 20, 2007

Key words: Static headspace GC-MS/Steam distillation GC-MS/Phenolics/Monoterpenes/Essential oils

Background: A comparative analysis by using static headspace (HS) and steam distillation (SD) GC-MS of the volatile and the semi-volatile secondary metabolites from leaves of cultivated Majorana syriaca.

Methods: The essential oils endogenous to cultivated thyme were isolated and identified by HS-GC-MS technology and compared to those from SD-GC-MS.

Results: The HS-GC-MS results showed that the Palestinian cultivated thyme is rich in monoterpene hydrocarbons and phenolic monoterpenes such as $\alpha$-phellandrene, $\alpha$-pinene, $\beta$-myrcene, $m$-cymene, $p$-cymene, $\gamma$-terpinene, thymol and carvacrol. In all the samples $\gamma$-terpinene, $p$-cymene, thymol and carvacrol were the most abundant compounds.

Conclusions: HS and SD-GC-MS have proved that most of the cultivated thyme samples examined has thymol isomer as the major phenolic constituent.

\section{INTRODUCTION}

Given its small area, the West Bank is one of the richest places in the world in plant biodiversity ${ }^{1}$. The Palestine valleys and mountains are covered with a huge number of plant species. Horticulture was known at Jericho more than 10,000 years ago, crops included wheat, barley, lentils, and peas ${ }^{2}$. About 2600 species exist on this small Mediterranean area, out of which more than 700 species are cited in ethnobotanical data and therefore named as Palestinian medicinal plants ${ }^{3}$. Many of these plant species have been used in folk medicine for the treatment of diseases ${ }^{1,3,4,5-8}$. One of the most popular herbs among Palestinians is thyme; its taxonomic name is Majorana syriaca L. Rafin (equal to Origanum syriacum var. syriacum).

The green leaves of the herb are rich in essential oil, which is responsible for its characteristic flavour and fragrance $^{9-11}$. Flowering of Majorana syriaca occurs from May to October ${ }^{12}$. Leaves are normally collected from wild populations once a year, before flowering. However, plants under cultivation are harvested three or four times a year. Cultivation of Majorana syriaca was initiated by transferring wild population growing in the central and northern parts of the West Bank to experimental fields particularly at the Ketf Al-wad area at the city of Jericho ${ }^{13}$. The production of cultivated thyme has increased dramatically in the recent years in response to the increasing local demands.

Oil of cultivated thyme is an important commercial product and is obtained mainly by steam distillation (SD) of the fresh leaves. The phenols, thymol and carvacrol are

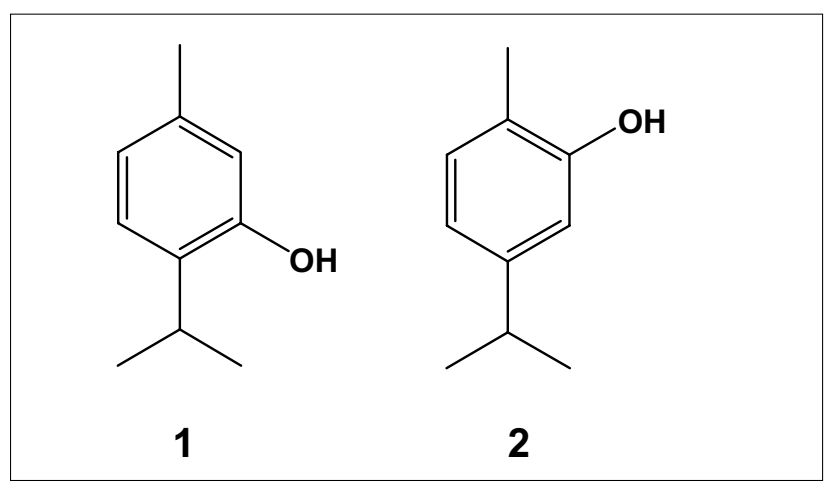

Fig. 1. Major natural phenolic compounds thymol (1) and its isomer carvacrol (2). 
the principal constituents of thyme oil (Fig. 1). In medicine, thymol has been the most valuable compound for medicinal purposes, but carvacrol, its isomer, preponderate in oils that are extracted from wild origin ${ }^{11,14,15}$.

The present work is a continuation to our previous work that explored the constituents in wild Palestinian thyme. The essential oils endogenous to cultivated thyme were isolated and identified by HS-GC-MS technology and compared to those from SD-GC-MS. Qualitative correlation of some of the parameters including harvesting time, location, and fresh water irrigation to the isomeric distribution of the major isomers in the thyme were investigated.

\section{MATERIALS AND METHODS}

\section{Plant collection}

Leaves of the Palestinian cultivated thyme samples were collected from six different environmental sites in the West Bank territories. The chosen sites were distributed geographically as follows: the northern area: Jenin and Tulkarim, the southern area: Hebron (Tarqumia, Halhool, Dora and Bet O"la), the central area: Bethlehem, and Ramalla and the eastern area: Jericho (Tab. 1).

The collection was carried out during the years 2003 and 2004. During this period, twenty-eight samples were collected. The cultivated thyme leaves were air dried in the absence of light at room temperature for a fixed period of time (three months) for all of the samples, followed by storage in sealed paper bags. This is the most effective method to preserve the components of the essential oils from being damaged or altered ${ }^{13}$. Leaves were analyzed by HS-GC-MS without being grounded. The amounts of the dry leaves used for the analysis were $0.6000 \mathrm{~g}$ and $6.0000 \mathrm{~g}$ for the HS and SD experiments respectively.

Table 1. Cultivated thyme samples collection from different areas in the West Bank.

\begin{tabular}{|c|l|l|c|}
\hline No. & Location & $\begin{array}{r}\text { Sampling site } \\
\text { district/subdistrict }\end{array}$ & $\begin{array}{c}\text { No. of culti- } \\
\text { vated samples }\end{array}$ \\
\hline 1 & South & Hebron / Tarqumia & 6 \\
\hline 2 & South & Hebron / Halhool & 1 \\
\hline 3 & South & Hebron / Dora & 2 \\
\hline 4 & South & Hebron / Bet O”la & 1 \\
\hline 5 & Center & Bethlehem / Menea & 5 \\
\hline 6 & Center & Ramalla / Kafer Malek & 4 \\
\hline 7 & East & Jericho / Ketf Al-Wad & 2 \\
\hline 8 & North & Jenin / Ya”bad & 4 \\
\hline 9 & North & Tulkarim / Rameen & 3 \\
\hline
\end{tabular}

\section{Reagents}

All the essential oil standards (thymol, carvacrol, $\alpha$ phellandrene, $\alpha$-pinene, $\beta$-myrecene $m$-cymene, $p$-cymene, $\gamma$-cymene, camphene, limonene, $\gamma$-terpenene, linalool, caryophellene), internal standard (4-isopropyl phenol), GC grade n-hexane and anhydrous sodium sulfate were all purchased from Sigma-Aldrich Inc. (USA).

\section{Equipment}

During the course of this research, the following equipment were used: Simple distillation system, analytical balance (Precisa, accuracy \pm 0.0001 , Switzerland), Rotary Evaporator (Bibby Sterlin Ltd. YK), Nylon membrane filters $(0.45 \mu \mathrm{m})$ were purchased from Whatman, Inc. (USA), PH meter, HM-30G, TOA electronics Ltd., (Japan).

\section{Instrumentation}

Essential oils from cultivated thyme were analysed using Shimadzu GC-17A connected to MS-QP5050A. The GCMS was operated in the electron impact ionisation mode (EI) at $70 \mathrm{eV}$. Shimadzu auto sampler AOC-20i was used with $2 \mathrm{ml}$ vials. An equilibrium headspace Shimadzu HSS-4A auto sampler was used with 27-ml HS vials. The HS vials were sealed with silicon rubber septa and aluminium caps after introduction of the thyme sample while the AOC vials were sealed with $8 \mathrm{~mm}$ double-faced rubber septa and screw cap with $12 \mathrm{~mm}$ hole. The GC is equipped with a fused silica capillary column; DB-5 MS containing ( $5 \%$ diphenyl polysiloxane, $95 \%$ dimethyl polysiloxane) $30 \mathrm{~m} \times 0.25 \mathrm{~mm}$ i.d., coating thickness is $0.25 \mu \mathrm{m}$, Supelco (Sigma-Aldrich Inc., USA).

\section{Extraction of the essential oil by Steam Distillation}

\section{Method A:}

Air-dried leaves of Magorana syriaca $(6.0000 \mathrm{~g})$ were mixed with $350 \mathrm{ml}$ of double distilled water (DDW) and $0.0300 \mathrm{~g}$ 4-isopropyl phenol as internal standard was added and subjected to steam distillation for $3 \mathrm{hrs}$ at atmospheric pressure. The water distillate containing oil was distributed two times with hexane ( $50 \mathrm{ml}$ each) by using a separatory funnel.

A 50-ml of $10 \%$ sodium hydroxide solution was added to the hexane layer and stirred at room temperature for 5 minutes and the two phases were separated. The aqueous fraction was washed with $50 \mathrm{ml}$ of hexane, and the hexane fractions were combined, dried with anhydrous sodium sulfate and were labelled as "non-phenolic" fraction. To the basic water layer, $1 \mathrm{M} \mathrm{HCl}$ was added with stirring until $\mathrm{pH} 3$. The solution was then extracted three times with hexane $(50 \mathrm{ml}$ each). The hexane fractions were combined and dried with anhydrous sodium sulfate and labelled as "phenolic" fraction. Aliquots $(1 \mu \mathrm{L})$ from the above solutions were injected to the GCMS. 
Table 2. Variation in yield of the essential oils in cultivated thyme leaves.

\begin{tabular}{|c|c|c|c|c|}
\hline \multirow[b]{2}{*}{ No. } & \multirow[b]{2}{*}{ District (subdistrict) ${ }^{1}$} & \multirow[b]{2}{*}{ Harvest time } & \multicolumn{2}{|c|}{ Yield } \\
\hline & & & Oil Wt. $(\mathrm{g})^{2}$ & $\%(\mathrm{~W} / \mathrm{W})^{3}$ \\
\hline 1 & H (Tarqomia) & May-2003 & 0.1262 & 2.103 \\
\hline 2 & $\mathrm{H}$ (Tarqomia) & June-2003 & 0.2334 & 3.890 \\
\hline 3 & H (Tarqomia) & June-2003 & 0.2498 & 4.163 \\
\hline 4 & H (Tarqomia) & February-2004 & 0.0963 & 1.605 \\
\hline 5 & H (Tarqomia) & March-2004 & 0.1194 & 1.990 \\
\hline 6 & H (Tarqomia) & May-2004 & 0.1445 & 2.408 \\
\hline 7 & H (Halhool) & May-2003 & 0.1457 & 2.428 \\
\hline 8 & H (Dora) & April-2004 & 0.2263 & 3.772 \\
\hline 9 & H (Bet O”la) & April-2004 & 0.2241 & 3.735 \\
\hline 10 & B (Menia) & February-2004 & 0.0797 & 1.328 \\
\hline 11 & B (Menia) & March-2004 & 0.1043 & 1.738 \\
\hline 12 & B (Menia) & April-2004 & 0.1967 & 3.278 \\
\hline 13 & B (Menia) & May-2004 & 0.2633 & 4.388 \\
\hline 14 & B (Menia) & June-2004 & 0.1790 & 2.983 \\
\hline 15 & R (Kafer Malek) & May-2003 & 0.1892 & 3.153 \\
\hline 16 & R (Kafer Malek) & March-2004 & 0.0806 & 1.343 \\
\hline 17 & R (Kafer Malek) & April-2004 & 0.1391 & 2.318 \\
\hline 18 & $\mathrm{R}$ (Kafer malek) & May-2004 & 0.2339 & 3.898 \\
\hline 19 & $\mathrm{~J}$ (Ya"bad) & March-2004 & 0.0812 & 1.353 \\
\hline 20 & $\mathrm{~J}$ (Ya”bad) & April-2003 & 0.1175 & 1.958 \\
\hline 21 & $\mathrm{~J}$ (Ya”bad) & May-2003 & 0.2330 & 3.883 \\
\hline 22 & $\mathrm{~J}$ (Ya"bad) & June-2003 & 0.2996 & 4.993 \\
\hline 23 & $\mathrm{~T}$ (Rameen) & April-2003 & 0.1693 & 2.822 \\
\hline 24 & $\mathrm{~T}$ (Rameen) & May-2003 & 0.1953 & 3.255 \\
\hline 25 & $\mathrm{~T}$ (Rameen) & June-2003 & 0.3150 & 5.250 \\
\hline 26 & Jr (Ketf Al-wad) & April-2003 & 0.1038 & 1.730 \\
\hline 27 & $\mathrm{Jr}$ (Ketf Al-wad) & May-2003 & 0.2897 & 4.828 \\
\hline
\end{tabular}

1 Northern areas: Jenin (J), Tulkarim (T); Southern area: Hebron (H); Central areas: Bethlehem (B), Ramallah (R); Eastern area: Jericho $(\mathrm{Jr})$.

2 Oil weight is based on dry weight. Approximately 6 grams of dry thyme leaves were accurately weighted. Dry samples were used rather than fresh in order to make a comparison between SD and HS. HS requires that the samples are dry since $100{ }^{\circ} \mathrm{C}$ used where the presence of water would damage the column.

${ }^{3}$ The percentage is based on weight-by-weight bases $(\mathrm{W} / \mathrm{W})$.

\section{Method B:}

Air-dried leaves of Majorana syriaca L. $(6.0000 \mathrm{~g})$ were mixed with $350 \mathrm{ml}$ of double distilled water and $0.0300 \mathrm{~g}$ 4-isopropyl phenol as internal standard was added and subjected to steam distillation for $3 \mathrm{hrs}$ at atmospheric pressure. The water distillate containing oil was distributed two times with hexane ( $50 \mathrm{ml}$ each) by using a separatory funnel. The hexane fractions were combined and dried with anhydrous sodium sulfate. A $0.2-\mathrm{ml}$ of this solution was diluted to $1 \mathrm{ml}$ with hexane and $1 \mu \mathrm{L}$ sample of it was injected to the GCMS.

\section{GC-MS operating conditions}

\section{A. Steam distillation samples}

The carrier gas flow rate was $1.6 \mathrm{ml} \mathrm{He} / \mathrm{min}$. Injector and detector temperatures were $230{ }^{\circ} \mathrm{C}$ and $250{ }^{\circ} \mathrm{C}$ respectively. Split ratio was 1:30. The column temperature was held at $60^{\circ} \mathrm{C}$ for 2 minutes, then raised from $60^{\circ} \mathrm{C}$ to $100{ }^{\circ} \mathrm{C}$ at $3{ }^{\circ} \mathrm{C} / \mathrm{min}$ and from $100^{\circ}$ to $280{ }^{\circ} \mathrm{C}$ at $30^{\circ} \mathrm{C} / \mathrm{min}$ and held there for $2 \mathrm{~min}$. Solvent cut time was 4 minutes and the starting time of the chromatogram was 5 minutes. Mass range was from 30 to $350 \mathrm{u}$, and scan interval was 0.5 seconds. Detector voltage was set to $1.50 \mathrm{kV}$. 
Table 3. Composition of the major essential oils components in cultivated Majorana syriaca in a different districts at different harvesting time by using HS and SD-GCMS.

\begin{tabular}{|c|c|c|c|c|c|c|c|c|c|c|c|c|}
\hline \multicolumn{13}{|c|}{$\%$ of the major components of essential oils in cultivated samples } \\
\hline \multirow[b]{2}{*}{ 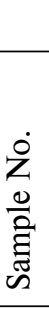 } & \multirow[b]{2}{*}{ 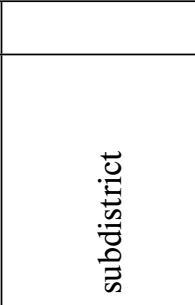 } & \multirow[b]{2}{*}{ 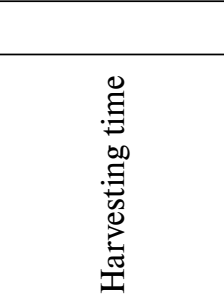 } & \multicolumn{8}{|c|}{ HS } & \multicolumn{2}{|c|}{ SD } \\
\hline & & & 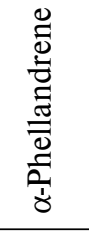 & 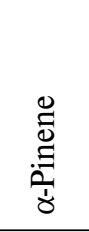 & 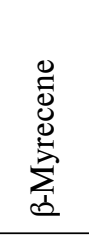 & 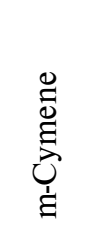 & 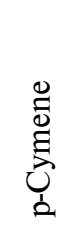 & $\begin{array}{l}\stackrel{0}{0} \\
\stackrel{0}{0} \\
\stackrel{0}{0} \\
\stackrel{0}{1} \\
\stackrel{1}{>}\end{array}$ & $\begin{array}{l}\overline{\mathrm{O}} \\
\stackrel{\mathrm{g}}{\mathrm{E}}\end{array}$ & $\begin{array}{l}\overline{0} \\
\bar{U} \\
\overline{\tilde{U}} \\
\text { U. }\end{array}$ & $\begin{array}{l}\overline{\overrightarrow{0}} \\
\text { ह્ } \\
\text { है }\end{array}$ & 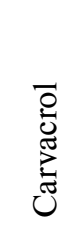 \\
\hline 1 & Tarqumia & May 2003 & 2.91 & 2.79 & 7.56 & 6.06 & 17.8 & 26.0 & 10.9 & 0.95 & 92.9 & 7.10 \\
\hline 2 & Tarqumia & June 2003 & 3.39 & 2.86 & 8.07 & 6.75 & 17.8 & 25.0 & 12.3 & 0.92 & 92.5 & 7.50 \\
\hline 3 & Tarqumia & June 2003 & 4.27 & 3.16 & 8.48 & 7.23 & 18.4 & 26.6 & 11.6 & 1.18 & 92.9 & 7.10 \\
\hline 4 & Tarqumia & February 2004 & 4.08 & 3.02 & 7.15 & 5.76 & 17.5 & 23.8 & 8.39 & 0.44 & 81.4 & 18.6 \\
\hline 5 & Tarqumia & March 2004 & 5.61 & 2.65 & 7.80 & 7.22 & 15.0 & 25.4 & 10.7 & 0.68 & 84.0 & 16.0 \\
\hline 6 & Tarqumia & May 2004 & 4.56 & 2.06 & 7.62 & 8.29 & 10.6 & 34.1 & 11.0 & 1.89 & 90.3 & 9.70 \\
\hline 7 & Halhool & May 2003 & 2.17 & 2.62 & 7.28 & 5.18 & 16.7 & 23.0 & 7.87 & 5.98 & 37.7 & 62.3 \\
\hline 8 & Dora & April 2004 & 5.55 & 2.06 & 6.64 & 7.35 & 17.6 & 26.1 & 9.17 & 5.28 & 59.1 & 40.9 \\
\hline 9 & Beit O”la & April 2003 & 6.90 & 3.03 & 9.22 & 7.23 & 13.7 & 27.5 & 8.37 & 3.62 & 58.3 & 41.7 \\
\hline 10 & Menia & February 2004 & 2.55 & 4.47 & 6.59 & 3.21 & 13.4 & 12.7 & 7.18 & 0.41 & 81.8 & 18.2 \\
\hline 11 & Menia & March 2004 & 4.65 & 2.45 & 6.66 & 5.57 & 21.1 & 24.2 & 5.52 & 2.58 & 66.4 & 33.6 \\
\hline 12 & Menia & April 2004 & 6.52 & 2.67 & 5.82 & 7.41 & 24.6 & 21.1 & 4.73 & 4.72 & 44.2 & 55.8 \\
\hline 13 & Menia & May 2004 & 5.37 & 2.43 & 7.72 & 7.56 & 11.5 & 30.0 & 9.05 & 6.49 & 76.8 & 23.2 \\
\hline 14 & Menia & June 2004 & 8.51 & 4.58 & 9.95 & 10.6 & 14.1 & 23.9 & 8.43 & 2.67 & 70.0 & 30.0 \\
\hline 15 & Kafer Malek & May 2003 & 2.81 & 3.3 & 8.18 & 5.91 & 18.9 & 26.3 & 12.7 & 0.95 & 92.0 & 8.00 \\
\hline 16 & Kafer Malek & March 2004 & 5.18 & 2.79 & 7.00 & 6.53 & 15.9 & 28.6 & 5.40 & 1.46 & 77.9 & 22.1 \\
\hline 17 & Kafer Malek & April 2004 & 5.29 & 2.67 & 6.76 & 7.60 & 18.0 & 29.8 & 7.52 & 0.41 & 94.9 & 5.11 \\
\hline 18 & Kafer Malek & May 2004 & 5.91 & 1.98 & 7.07 & 6.81 & 16.4 & 21.0 & 11.9 & 0.86 & 88.4 & 11.6 \\
\hline 19 & Ya"bad & April 2003 & 5.16 & 3.59 & 6.89 & 5.77 & 14.2 & 28.1 & 5.56 & 5.84 & 53.1 & 46.9 \\
\hline 20 & Ya"bad & May 2003 & 3.89 & 3.03 & 7.74 & 7.45 & 20.8 & 29.1 & 8.43 & 1.16 & 81.8 & 18.2 \\
\hline 21 & Ya"bad & June 2003 & 4.65 & 2.45 & 6.66 & 7.57 & 21.1 & 24.2 & 5.52 & 2.58 & 85.5 & 14.5 \\
\hline 22 & Ya"bad & March 2004 & 5.16 & 3.59 & 6.89 & 5.77 & 14.2 & 28.1 & 5.56 & 5.84 & 71.7 & 28.3 \\
\hline 23 & Rameen & April 2003 & 3.71 & 3.37 & 8.33 & 6.77 & 17.8 & 26.8 & 8.33 & 5.03 & 57.5 & 42.5 \\
\hline 24 & Rameen & May 2003 & 2.37 & 2.75 & 7.79 & 5.70 & 18.2 & 23.8 & 7.75 & 5.50 & 43.6 & 56.4 \\
\hline 25 & Rameen & June 2003 & 3.30 & 3.15 & 8.68 & 6.96 & 20.0 & 24.2 & 8.41 & 2.79 & & \\
\hline 26 & Ketf Al-wad & April2003 & 4.22 & 3.46 & 8.93 & 7.26 & 20.2 & 25.2 & 8.28 & 2.00 & 71.2 & 28.8 \\
\hline 27 & Ketf Al-wad & May 2003 & 3.53 & 2.90 & 8.65 & 7.55 & 16.7 & 27.0 & 10.38 & 0.85 & 93.1 & 6.92 \\
\hline
\end{tabular}

\section{B. Headspace samples}

The operating conditions were similar to that described in section A for the steam distillation samples except for the following: vial temperature was set to $100^{\circ} \mathrm{C}$ and the syringe temperature was set to $110^{\circ} \mathrm{C}$. The volume of the thyme headspace injected to the GCMS capillary column was $0.2 \mathrm{ml}$.

\section{Procedure of the GC-MS analysis}

\section{A. Steam distillation samples}

$1 \mathrm{ml}$ of the hexane solution samples was placed in $2 \mathrm{ml}$ vial and $1 \mu \mathrm{l}$ was injected. Before each injection the syringe of the autosampler was rinsed twice, first with the solvent (hexane), and then with the sample solution.

\section{B. Headspace sampling}

Before each HS-GCMS analysis, a blank consisting of an empty vial is carried out to check whether any consti- 
tuents of the materials of the septum or the vial are being emitted. $0.6000 \mathrm{~g}$ samples of dried leaves of thyme were placed in HS vials and immediately sealed with silicone rubber septa and aluminium caps. The vials were then transferred to the headspace tray.

\section{B.1 Equilibration temperature}

To reach the optimal conditions for HS analysis, five different temperatures were chosen at 40,60,80, 100, and $120^{\circ} \mathrm{C}$ at fixed equilibration time.

\section{B.2 Equilibration time}

To select an optimal equilibration time for the extraction of the essential oils in the thyme, vials were equilibrated at 10, 20 and 30 minutes at fixed temperatures. Analyses were performed in triplicates.

\section{Peaks identification}

The identification of the compounds was based mainly on their retention times in comparison with those from authentic standards. The standards were injected separately in addition to adding them to the thyme matrix (spiking) to enhance the relevant peaks of interest. Identification of some peaks was based on matching of their MS spectra with NIST/EPA/NIH Mass spectral library (NIST 98).

\section{RESULTS AND DISCUSSION}

Yield of cultivated thyme oils

The essential oils of cultivated Majorana syriaca leaves were isolated by normal steam distillation. The thyme samples were collected from twenty-seven individual plants cultivated in six populations from Palestine. The collections were made between the years 2003 and 2004. The harvesting time, location and origin of thyme (i.e., cultivated) effects on the yield of essential oils are summarised in Table 2.

From Table 2 it is obvious that there are distinct differences in oil yield when comparison is made between the following:

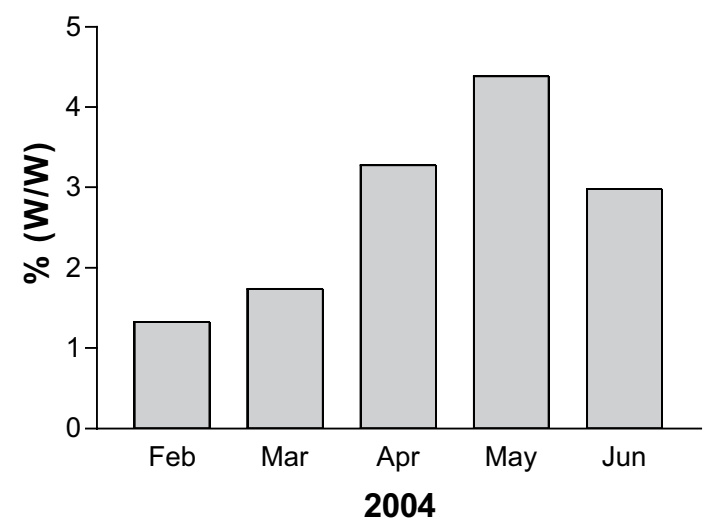

Fig. 2. Left part, Thyme oil $\%(\mathrm{~W} / \mathrm{W})$ at different harvesting time isolated from cultivated samples collected from Hebron (Tarqumia); Right part, Thyme oil \% (W/W) at different harvesting time isolated from cultivated Samples collected from Bethlehem (Menea).
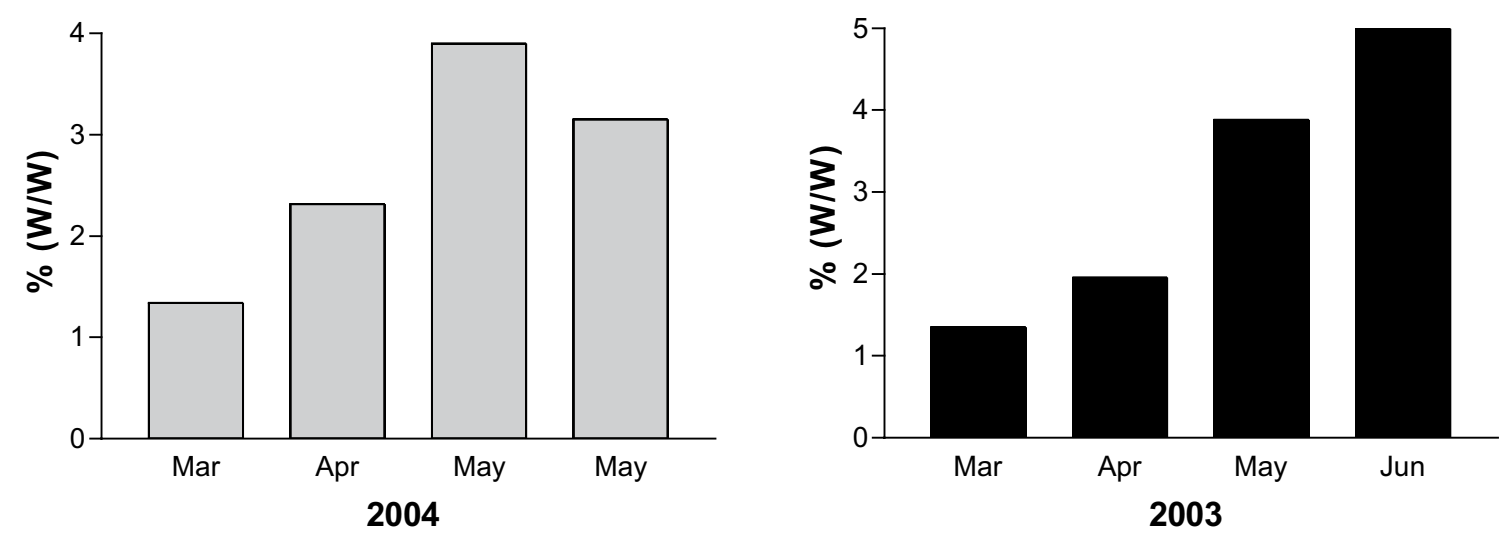

Fig. 3. Left part: Thyme oil $\%(\mathrm{~W} / \mathrm{W})$ at different harvesting time isolated from cultivated samples collected from Ramallah (Kafer Malek); Right part, Thyme oil \% (W/W) at different harvesting time isolated from cultivated samples collected from Jenin (Ya'bad). 

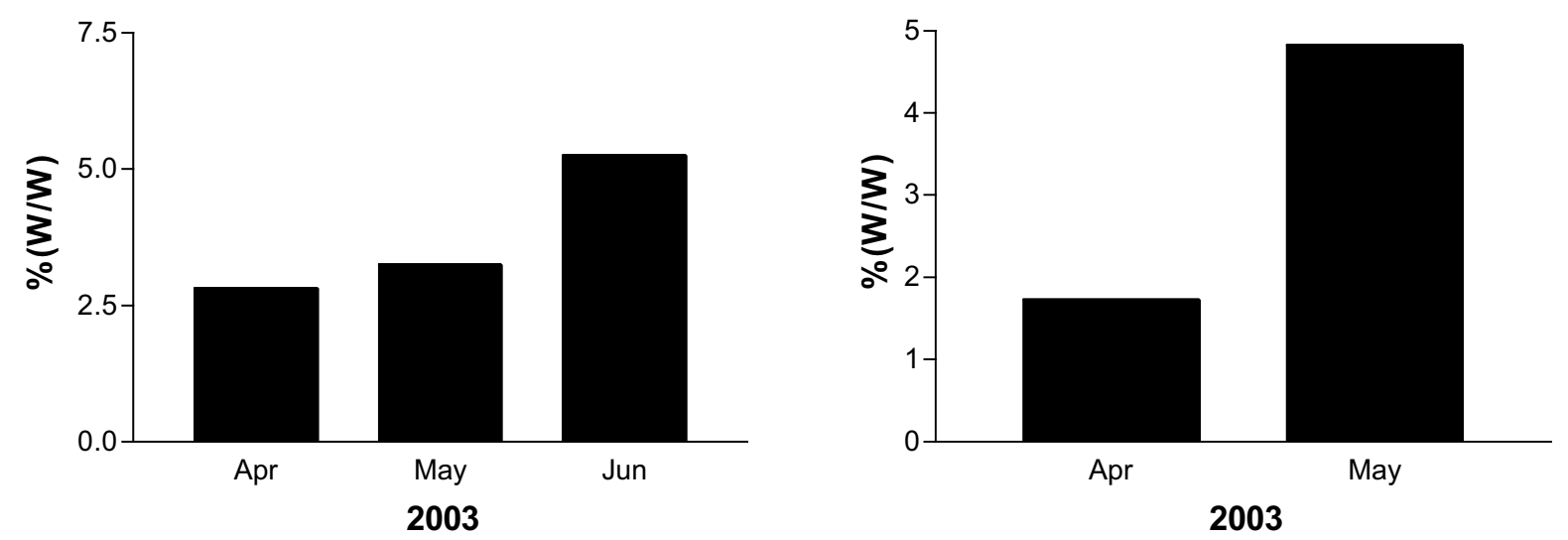

Fig. 4. Left part, Thyme oil $\%(\mathrm{~W} / \mathrm{W})$ at different harvesting time isolated from cultivated samples collected from Tulkarim (Rameen); Right part, Thyme oil \% (W/W) at different harvesting time isolated from cultivated samples collected from Jericho (Ketf Al-Wad).
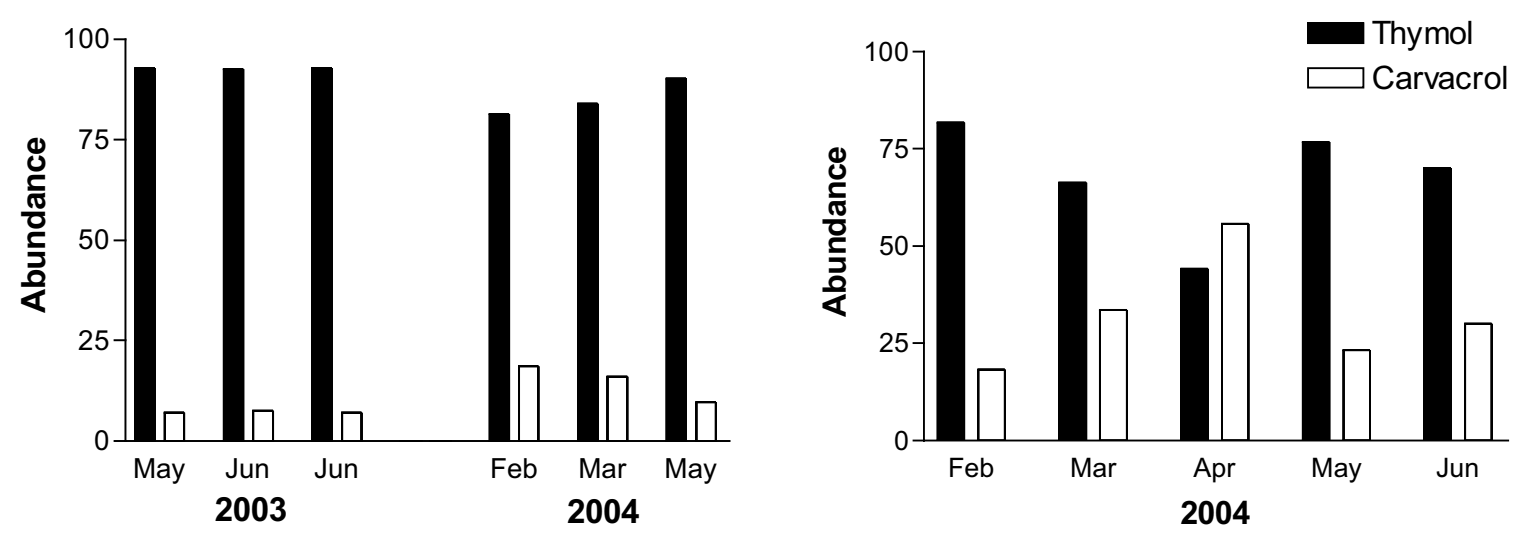

Fig. 5. Left part, Histograms of the isomeric distribution of thymol and carvacrol from cultivated sampe from Hebron (Tarqumia) at different harvesting time by SD-GCMS; Right part, Histograms of the isomeric distribution of thymol and carvacrol from Bethlehem (Menea) at different harvesting time by SD-GCMS.

Wild vs. cultivated thymes

The yield of the essential oils from cultivated thyme ranged from $1.328 \%$ (Bethlehem, Menia, February 2004) to $5.52 \%$ (Tulkarim, Rameen, June 2003). The differences in the yield of the cultivated samples are as much as $74.7 \%$. Almost the same observation was noticed when different wild thyme samples from different locations were examined ${ }^{11}$.

This result simply indicates that harvesting the thyme in May-June months would produce more essential oils than earlier in the year, namely, January-March months no matter what type of thyme was isolated (Fig. 2-4). A possibility of variation in the oil yield may be attributed to the vegetation stages of the natural plant growth. Usually flowering of thyme occurs from May to June (Fig. 2-4). According to Dudai et. al. ${ }^{12}$ leaves are normally collected from wild thyme populations once a year between March and April, just before flowering. This finding gives oil industries some degree of control over the amount of essential oil of thyme produced upon distillation. It is worthwhile mentioning that drying the leaves of thyme causes a dramatic decrease in the amount of water especially of the irrigated thyme, hence increasing oil percentage. Therefore, there is no significant contribution apparently to the type of thyme (i.e., wild vs. cultivated) on the yield of the total oil.

\section{Sampling sites}

Our study reveals that there are no dramatic differences in the oil yields as it related to different geographical sites (Tab. 2).

\section{Steam distillation (SD) and GC-MS analysis}

Upon SD of the cultivated thyme samples that were collected as shown previously (Tab 2 ) a relatively acceptable percentage of the oil was obtained (1.3-5.5\%) based on dry weight. GCMS analysis reveals that the oil contained mainly the semi-volatile phenolic isomers, namely, carvacrol and thymol. None of the volatiles, particularly, p-cymene and $\gamma$-terpinene, appeared in the TIC analysed samples. This is most probably related to the method of sample preparation, which involved concentration of hex- 

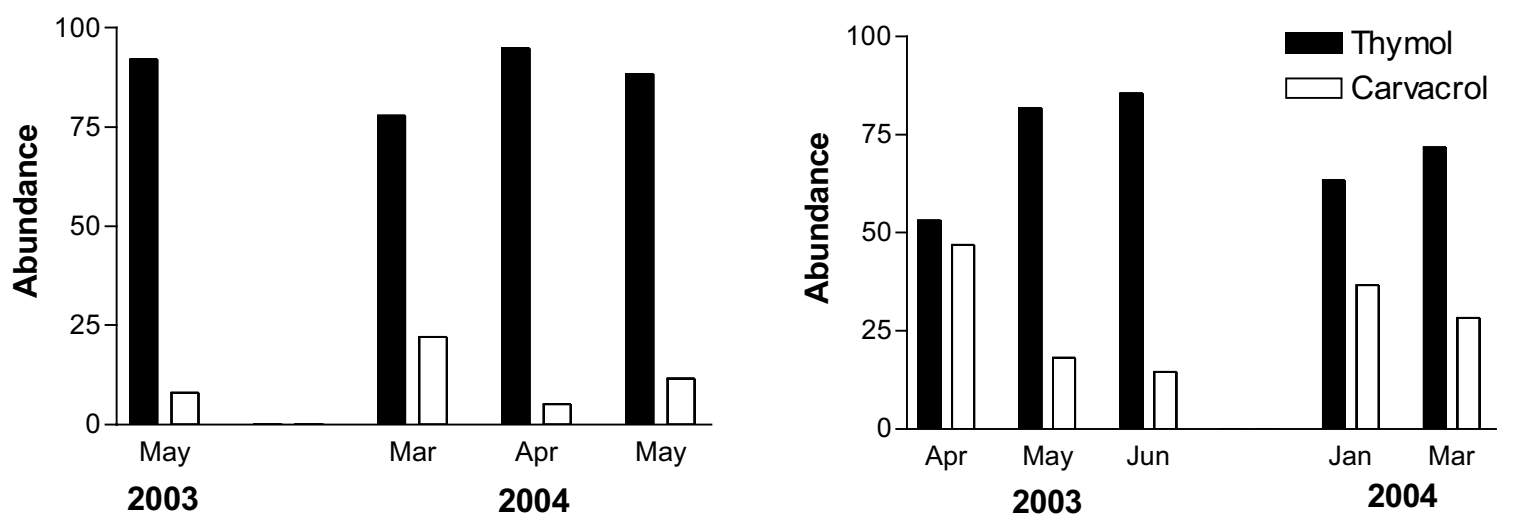

Fig. 6. Left part, Histograms of the isomeric distribution of thymol and carvacrol from Ramallah (Kafer Malek) at different harvesting time by SD-GCMS; Right part, Histograms of the isomeric distribution of thymol and carvacrol from Jenin (Ya”bad) at different harvesting time SD-GCMS.
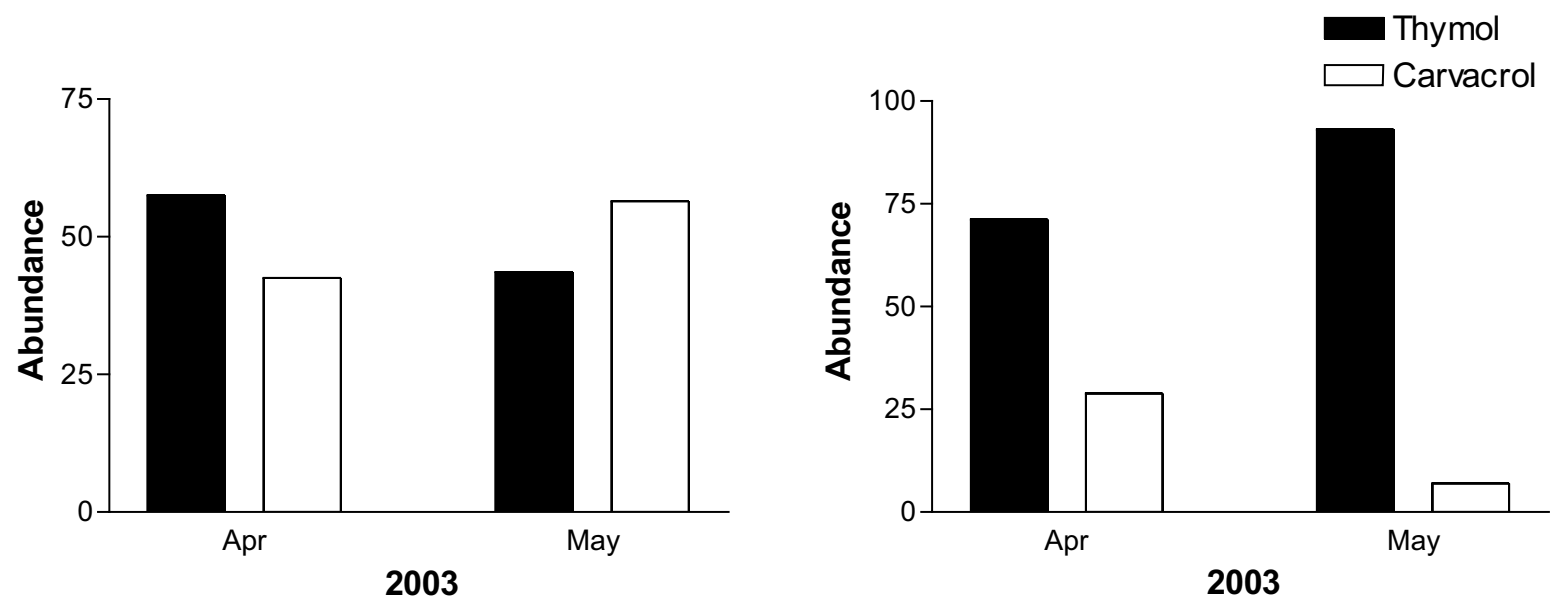

Fig. 7. Left part, Histograms of the isomeric distribution of thymol and carvacrol from Tulkarim (Rameen) at different harvesting time by SD-GCMS; Right part, Histograms of the isomeric distribution of thymol and carvacrol from Jaricho at different harvesting time by SD-GCMS.

ane solvent volume on high vacuum. Nevertheless, the ratio of phenolic isomers reflected almost exactly the ratio we have seen when analysing the thyme leaves using the HS technique after peak normalization. An interesting variation appeared when the comparison is made between the wild thyme and the cultivated one. Almost exclusively the wild samples contained carvacrol as the major constituent ${ }^{11}$, while the cultivated samples contained thymol as the major isomer.

This variation appears to be related to the water stress and is not affected significantly by the geographical location or the harvesting time (Fig. 5-7). This is consistent with previous work that appeared in the literature lately ${ }^{16}$. Thus the ratio of carvacrol to thymol in the wild sample obtained from northern areas (Nablus/Beta) in June 2003 , for example, is $85.8 \%: 14.2 \%$, while the ratio for the cultivated sample obtained from southern areas (Hebron/ Tarqumia) in June 2003 is $7.10 \%: 92.9 \%$ (Tab. 3) ${ }^{11}$. On the other hand, the ratio of carvacrol to thymol in the wild sample obtained from Ramallah (Kafer Malek) in June 2003 is $86.1 \%: 13.9 \%$ while the ratio for the cultivated sample obtained from the same location in March 2004 is $22.1 \%: 77.9 \%$ respectively. This observation is almost consistent in most of the samples studied (Fig. 5-7). The dominance of thymol over carvacrol isomer in cultivated thyme by using SD-GCMS is depicted in Fig. 8.

\section{Static Headspace (HS) and GC-MS analysis}

In Palestine, little information is available dealing with local thyme. Nonetheless, there is an investigation conducted by using GC-FID analysis on very limited number of thyme samples ${ }^{17}$. We have investigated wild thyme by using HS-GCMS for the first time ${ }^{11}$. The optimal HS parameters chosen were $10 \mathrm{~min}$ of equilibration time and $100{ }^{\circ} \mathrm{C}$ of vial temperature ${ }^{18}$. Figure 9 shows a typical HS-GCMS chromatogram of a cultivated thyme at the optimised conditions of temperature and time. Baseline separation with good resolution was obtained for almost all the compounds separated (Fig. 9). The results of the HS-GCMS of all the samples appear in Table 2 show obvious differences in the percentages of essential oil constituents as follows: 


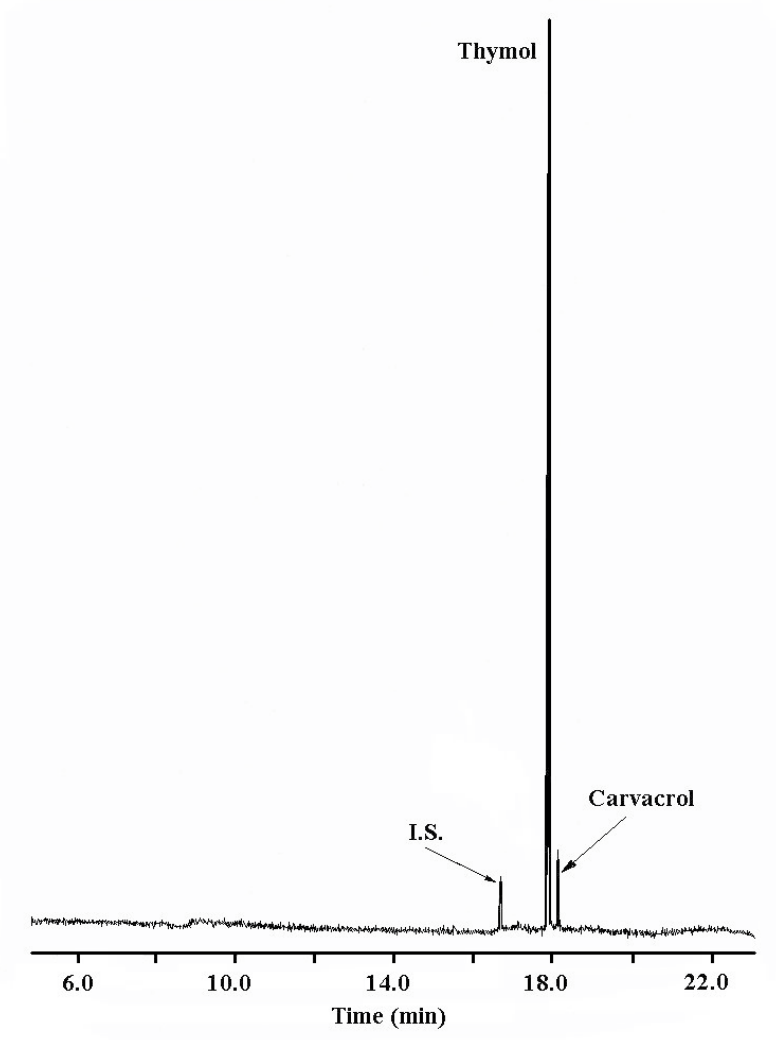

Fig. 8. Typical TIC of SD-GCMS of cultivated thyme sample harvested from Hebron (Tarqumia) by using DB-5 capillary column. Chromatographic conditions are stated in the experimental sections. I.S stands for the internal standard (4-isopropylphenol) that has been used for quantification of thymol and carvacrol.

Thymol vs. Carvacrol percentages

Thymol and carvacrol are isomers that have boiling points of $232{ }^{\circ} \mathrm{C}, 237^{\circ} \mathrm{C}$ respectively. Hence thymol gets eluted earlier than carvacrol in the GCMS (Fig. 8,9). We noticed that the wild growing Palestinian thyme is characterised by the dominant presence of carvacrol irrespective of the harvesting time or the location. Conversely, fresh water irrigation (cultivated) has revealed predominance of the thymol isomer concentration (Fig. 8,9 and Tab. 3). This consistent result explains why wild thyme, which is rich in carvacrol, has a distinct worm pungent taste a distinctive property of carvacrol ${ }^{19}$.

Variations in major essential oils components

The HS-GC-MS analysis showed that the cultivated thyme oils are rich in monoterpene hydrocarbons and phenolic monoterpenes. The results are summarised in Table 3. HS analysis revealed that the major constituents identified throughout all the harvesting periods were varied greatly among the thymes examined and were as the following: $\alpha$-phellandrene (2.17-8.51\%), $\alpha$-pinene (1.98-4.58 \%), $\beta$-myrecene (5.82-9.95\%), m-cymene (3.21-10.6\%), $p$-cymene $(10.6-24.6 \%), \gamma$-terpinene (12.7-34.1\%), thymol (4.73-12.7\%), carvacrol (0.41-

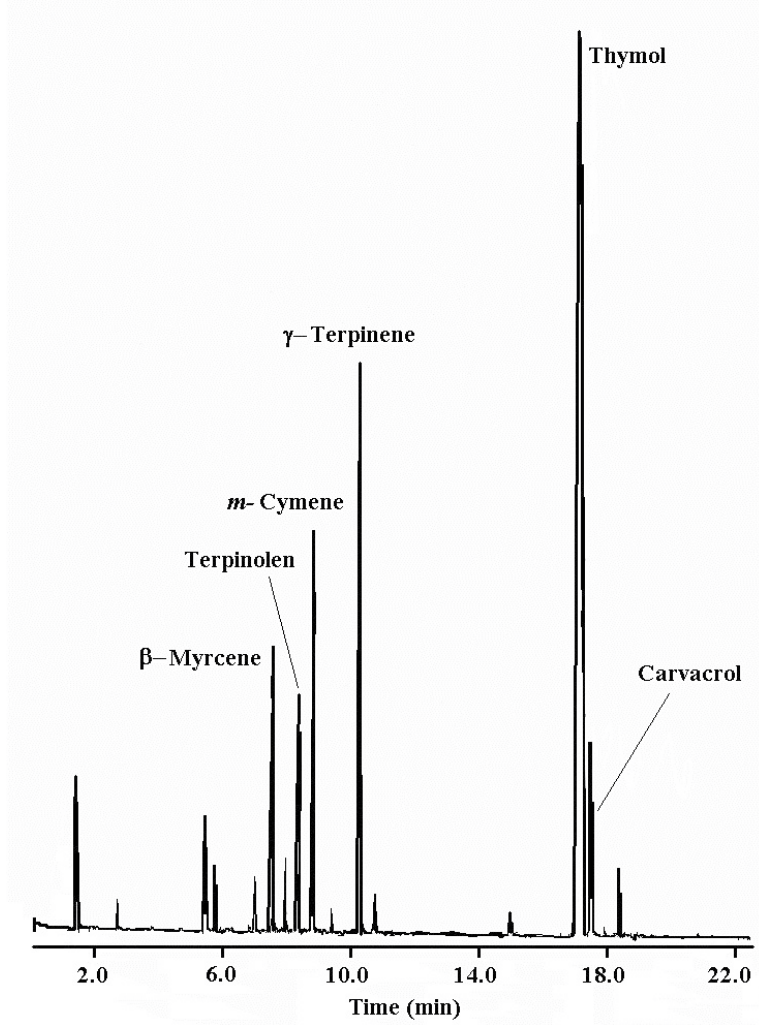

Fig. 9. Typical TIC of the HS-GC-MS of cultivated thyme sample harvested from Hebron (Dora) using DB-5 capillary column.

$5.98 \%$ ) (Table 3). It is important to notice at this point, that the percentages did not reflect quantitative amounts of these components. In all samples, the most abundant monoterpenes were $\gamma$-terpinene and p-cymene (Fig. 9), the biogenetic precursors (via enzymic hydroxylation) of the phenolic terpenes thymol and carvacrol. The percentages of $\gamma$-terpinene were icreased during February, March and April while decreased in May. The percentages of $p$ cymene were icreased during February, March and April while decreased in May. Thymol was icreased during May in cultivated samples (Tab. 3 ).

Comparison between HS and SD- GCMS analysis of cultivated thyme

We have developed a sensitive and rapid SD,HSGCMS methods for analysis of volatile, and semivolatile compounds in Palestinian cultivated thyme. Although both the HS and SD complement each other, the combined HS with GCMS has certain advantages over SD technique that have been used in cultivated thyme extraction. It senses directly all volatile and semivolatile terpenoids present in thyme examined whereas using SD large amounts of the volatiles escape, leaving only the semivolatiles, namely thymol and carvacrol isomers. 
Upon careful comparison between the isomeric distribution of thymol and carvacrol in SD and HS, we found that the isomeric ratios using both methods are very close to each other. Therefore, HS technology would offer faster, reliable, and simultaneous method for the determination of essential oils present in Palestinian thyme.

\section{REFERENCES}

1. Al Sheikh B, Salman M, Masalha J, Salem K, Ron M, Shmida A. Preliminary Checklist and Ecological Data-Base of Plants of the West Bank. Al Quds University, Abu Deis, West Bank, 2000, A-B.

2. Feinbrunn N. New data on some cultivated plants and weeds of early bronze age in Palestine. Palestine J Bot 1938; 1:238-240.

3. Shtayeh AMS, Yaghmour RMR, Faidi YR, Salem K., Al-Nuri MA. Antimicrobial activity of 20 plants used in folkloric medicine in the Palestinian area. J Ethnopharmcol 1998; 60:265-271.

4. Halim A F, Mashaly MM, Zaghloul AM, Abd El-Fattah H, De Pooter HL. Chemical constituents of the essential oils of Origanum syriacum and Stachys aegyptiaca. Int J Pharmacogn 1991; 29:183187.

5. Rivera D, Inocencio C, Obon C, Carreno E, Reales A., Alcaraz F. Archaeobotany of capers (Capparis) (Capparaceae). Veg Hist Archeobot 2002; 11:295-313.

6. Dutau G. The risk of allergy to dietary and medicinal products. Rev Franc Allergol Immunol Clin 2004; 44:634-645.

7. Nam SH., Kang MY. Antioxidant activity of 13 medicinal plants. Pharm Biol 2004; 42:409-415.

8. Scherrer AM, Mott, R., Weckerle CS. Traditional plant use in the areas of Monte Vesole and Ascea, Cilento National Park (Campania, Southern Italy). J Ethnopharmcol 2005; 97:129-143.

9. Dembitsky VM, Goldshlag P, Srebnik M. Occurrence of dicarboxylic (dioic) acids in some Mediterranean nuts. Food Chem 2002; 76:469-473.
10. Kraft P., Swift KAD. Perspectives in Flavor and Fragrance Chemistry, First Edition, 250 Pages, Verlag Helvetica Chimica Acta, Zürich; 2005.

11. Abu-Lafi S, Odeh I, Dewik, H., Qabajah M., Hanuš LO, Dembitsky VM. Comparison analysis by static headspace and steam distillation GC-MS of volatile secondary metabolites from leaves of wild Palestinian Majorana syriaca. 2007 (unpublished)

12. Dudai N, Putievsky E, Palevitch D, Halevy AH. Environmental factors affecting flower initiation and development in Majorana syriaca L. (=Origanum syriacum var. syriacum). Isr J Bot 1989; 38:229-239.

13. Werker E, Ravid U, Putievsky E. Structure of glandular hairs and identification of the main components of their secreted material in some species of the labiatae Isr J Bot 1985; 34:31-45.

14. Cosentino S, Tuberoso CIG, Pisano B, Satta M, Arzedi E, Palmas F. In-vitro antimicrobial activity and chemical composition of Sardinian Thymus essential oils. Lett Appl Microbiol 1999; 29:130-135.

15. Arnold N, Bellomaria B, Valentini G. Composition of the essential oil of three different species of Origanum in the eastern Mediterranean. J Essen Oil Res 2000; 12:192-196.

16. Dudai N, Putievsky E, Ravid U, Palevitch D, Halevy AH. (Monoterpene content in Origanum syriacum as affected by environmental conditions and flowering. Physiol Plant 1992; 84:453459.

17. Ishaq J., El-Yousef S. Isolation of essential oils of Palestinian thyme by GC/FID. Bethlehem University J. 1985; 4:162-175.

18. Abu-Lafi S, Dembick, JW, Goldshlag P, Hanuš LO, Dembitsky VM. The use of the 'Cryogenic' GC/MS and on-column injection for study of organosulfur compounds of the Allium sativum. J Food Comp Anal 2004; 17:235-245.

19. Dudai N, Werker E, Putievsky E, Ravid U, Palevitch D, Halevy AH. Glandular hairs and essential oils in the leaves and flowers of Majorana syriaca. Isr J Bot 1988; 37:11-8. 